\title{
Edgard Navarro e o escracho da história
}

Geraldo Blay Roizman ${ }^{1}$

\footnotetext{
${ }^{1}$ Geraldo Blay Roizman é cineasta e artista plástico desde 1989, formado em Arquitetura e Urbanismo pela PUCCAMP 1987, com Mestrado em Artes Visuais pelo instituto de Artes da UNESP/SP intitulado "Mário Peixoto, um olhar fenomenologico" de 2003. Doutorado concluído em junho de 2019 no Programa de Pós-Graduação em Meios e Processos Audiovisuais, Linha de Pesquisa: História, Teoria e Crítica na Escola de Comunicações e Artes da Universidade de São Paulo intitulado: Os Superoutros: "Corpos em movimento no cinema superoitista dos anos 1970 no Brasil".

Email: geblayroiz@ig.com.br
} 


\section{Resumo}

Se fossemos localizar O Rei do Cagaço (1977) dentro do universo cinematográfico de Edgard Navarro, ele faria parte, de forma mais geral, do chamado surto superoitista no Brasil, e do grande ciclo de filmes realizados em Super-8 na década de 70 que participaram de festivais da época, especificamente das chamadas Jornadas de Cinema da Bahia, e que possuíam, em geral, um forte teor provocativo ao mesmo tempo poético e político, e principalmente um sentido muito preciso de despojamento na flexibilização da linguagem possibilitada pela novidade da bitola.

Palavras-chave: Edgard Navarro; Super-8; contracultura.

\section{Abstract}

If we were to locate O Rei do Cagaço (1977) within Edgard Navarro's cinematic universe, he would be part, more generally, of the so-called superoitist outbreak in Brazil, and of the great cycle of films made in Super-8 in the 70's. they participated in festivals of the time, specifically the so-called Bahia Film Days, which had, in general, a strong provocative content, at the same time poetic and political, and especially a very accurate sense of the flexibility of language made possible by the novelty of the gauge.

Keywords: Edgard Navarro; super-8; counterculture. 
Estes filmes provocadores, estimulados pelo contexto das Jornadas, fizeram parte, como o próprio diretor nomeia, da chamada "tríade freudiana", junto com Alice no país das mil novilhas, de 1976 e Exposed, de 1978. Essa qualidade provocativa se tornaria mais do que uma peculiaridade, um verdadeiro estilo, a partir de um agudo sentido estético de experimentação. A utilização original da câmera Super-8 como produto de consumo para o lazer doméstico, na mão de artistas e poetas, vai adquirindo, como diz Machado, olhares mais inquietos sobre a cidade e sua fauna urbana, sobre as locações turísticas, descobrindo aos poucos as potencialidades expressivas da bitola.

A questão mais importante, principalmente no caso de Navarro, será epatér la burgeoisie, ou surpreender a expectativa e romper com um comportamento dito respeitável. O corpo, neste sentido, se apresentaria neste momento histórico como eixo fundamental de quebra de padrões no que tange à possibilidade da manutenção da existência do individual, do particular e o superoitismo veio juntar este engajamento ao universo cinematográfico de democratizar o processo artesanal ao nível do faça você mesmo, libertador, portanto, de esquemas de produção num momento do país da explosão da tensão entre forças sociais conservadoras e repressivas e as libertárias vinculadas à contracultura, ao tropicalismo, ao sexo, drogas e rock and roll, o comportamento outsider, hippie, a loucura e a psicodélica. Essa explosão seria refletida no interior da expressividade gestada na própria vida pregressa do cineasta, de formação escolar em colégio de padres e repressão ao corpo.

Este transbordamento se dará através de um dizer que se expressará no Super-8 principalmente através do corpo, por meio do escracho nas imagens e na locução livre que serão então utilizados por Navarro de uma forma prosaica, contrastados com as imagens de gestos corpóreos subversivos relativos à ordem social e que funcionam como destutelamento neste momento repressivo: o sujar a rua e atacar os carros com excremento, o andar de calças folgadas e sem camisa, o afanar a comida de outrem, o pegar carona e afanar o carro, o atacar as nádegas das moças com um canivete, o assaltar, o tocar sanfona na praça, o correr à esmo e o dançar ou se equilibrar nos próprios pés sobre uma linha imaginária ou o brincar louco de super-heróis na praça junto com a inversão sexual carnavalesca como subversividade, recheados pela troça verbal, permeiam o tecido fílmico de $O$ rei do cagaço.

A figura do louco, o louco varrido ou louco da aldeia, funcionaria aqui como instrumento expressivo libertário para além do conservadorismo moral tanto da própria vida do cineasta como da geração anterior, na possibilidade de relativização da ideia de bem e de mal. Esse modo de expressão destutelado faria com que os cineastas do Super-8 nos festivais e nas jornadas de cinema ficassem com o estigma de serem 
criativos, porém irresponsáveis, portanto sem compromisso ideológico, sendo pejorativamente tomados como cineastas de curtição.

Essa geração do chamado "desbunde", tinha, no entanto, uma atitude de enfrentamento no campo do comportamento, levantando questões relativas à sexualidade, experimentações com drogas e novas propostas de linguagem, e estas discussões e debates, por vezes acalorados, acabaram, em última instancia, como nos lembra Izabel Melo, dando sentido á própria Jornada de Cinema na Bahia. A característica geral dos filmes superoitistas seria exatamente a de um gracejo bombástico e descompromissado de imagens e sons tomados ali, no calor da hora, quase sem roteiro prévio e com teor libertário, ou talvez fosse melhor dizer, incendiário, apesar da película superoitista ser de acetato e não mais de nitrato.

A particularidade de Navarro, para além do fato de que, como o cineasta baiano Pola Ribeiro dizia, "o Super-8 viria para jogar merda nos monumentos", é que ele instauraria uma poética experimental viva na leveza do "quase nada" que é a leveza da câmera na mão, que encontra as imagens sujas, como as mãos singelas das crianças encontram e se lambuzam das cores nas tintas nas bricolagens dos papéis no início do filme, ou os loucos que também criam seus mundos com as coisas e lugares ao redor, e que fazem com que a insignificância significativamente torta do superoitismo, feita quase somente de diabruras subversivas da fala, da "cáca", da cola e acetato, adquiram sentido até hoje. É na linguagem em seus dois aspectos, "brinquedo e enfermidade", que se estabelece o pensamento de Navarro como realizador através do desejo da contaminação Pop e tropicalista neste filme pela mistura de imagens, entoação, inflexões e gestos vocais $^{2}$, pela palavra performatizada enquanto escracho, e poderíamos dizer que este seria o lugar onde melhor se apreenderia a relação entre o corpo e aquilo tudo o que ele pode enquanto política.

De forma geral, tanto o gestual das crianças no início do filme como o comportamento destutelado dos personagens e dos gestos vocais escrachados evocariam o que Nietzsche proporia como "superar a ambivalência dos instintos e restaurar a unidade dos contrários que existiria na infância” e, dessa forma, se a repressão pudesse ser superada, a vida não estaria no tempo histórico, por que a repressão transformaria a compulsão atemporal do instinto a repetir em dialética um movimento para frente da neurose que é a história.

Navarro então se expressaria neste filme através da referência escrachada da fase anal na psicologia em Freud, que atua como um mote de des-repressão e que poderia se instaurar como fator libertário formal e expressivo principalmente através da busca 
do prazer. Esta ludicidade se daria através do brincar das crianças no início e se ligaria ironicamente, ao duplo sentido da palavra "relaxamento", primeiro no sentido da voz macia do rádio narrando a preparação da yoga, e que cruzaria em seguida com o relaxamento necessário ao próprio ato excremental filmado em close up junto ao cinismo irônico da voz que diz ao mesmo tempo em tom de esforço: é preciso tentar.

Este "presente" dado ao espectador, de intenção desmoralizadora, se ligaria freudianamente a busca do prazer obtido na infância através da atividade de qualquer órgão do corpo humano, a chamada perversão polimorfa, que será utilizada pelo cineasta como incontinência social funcionando como um mote principal para a série progressiva de ataques aos monumentos da cidade referentes ao que o filme cumprirá como escracho até o fim, tendo em mira o momento da repressão política. Essa incontinência surge no filme tanto através de gestos como do dizer tudo, simulando sons do rádio, das colagens das crianças ao cinzelamento na película, do surtado, do psicótico com touca de banho a atacar as nádegas das mulheres em contraponto à Igreja e á rádio como motes culposos. Do contracultural caronista ao folgado no restaurante, dos personagens loucos bizarros e carnavalescos soltos na praça com seus gestos lúdicos de crianças adultas ao atentado ao pudor na proliferação do ataque das fezes na cidade, todos se apresentariam como contrastes aberrantes ao socius, reflexo em alguma medida de uma possível neurose obsessiva narcísica do próprio cineasta.

Mas esse traço (na expressão de Waly Salomão) de anarcisismo em Navarro seria compensado pela dessacralização da intelecção psicanalítica tanto na própria ausência de uma referência literária balizadora do enredo como pelo uso da voz performatizada no filme. Das falas despudoradas do "concurso de peidos, a retenção anal", o esforçoso "é preciso tentar" ou o escandaloso aburguesado "não suje meu tapete" até o reproduzido e bem humorado palavrório nonsense brasileiro" de José Vasconcelos, que escracha o saber culto ou o inútil empoderamento do conhecimento catedrático; também o uso cômico do rádio popular como em Sgarzerla, que denuncia ao mesmo tempo que se alimenta da barbárie, das músicas bregas-tropicalistas inseridas no filme, a Pra Chatear de Caetano, cantada por Ronnie Von, a Soneca contra o Barão Vermelho até a cafona Prisioneira do Amor 1970, de Rita Lee, todas essas vozes juntas operariam através de um caldo da palavra performática com o sentido do se poder "dizer tudo" ou como abertura para a possibilidade do dizer, funcionando sonoramente, assim como na imagem, como um esvaziamento dos intestinos.

Tudo isso iria de encontro a pensar numa potência do superoitismo experimental como algo paralelo ao tema do menor em Deleuze quando olha para o teatro e o cinema de Carmelo Bene, para além do próprio esquema precário de produção, do acionamento da gestualidade corpórea e pelo brincar com a linguagem em gravações caseiras 
inserindo, gravando e editando sons ludicamente numa fita cassete como também fazia Bene na construção de uma assembleia de vozes gravadas e vivas sobrepostas em uma pontuação complexa. Abordar a minoridade apenas seria tornar-se estrangeiro em sua própria língua, mas tornar a linguagem um gaguejar expressivo através de seu caráter performático. Haveria aqui, portanto, uma articulação do individual com o político e a subtração de elementos do poder: o pai, a família, o estado, a polícia, o roteiro e a produção do cinema mainstream, que aconteceria desde a ausência de diálogo ao longo de todo o filme, o comportamental grotesco e infantilóide do terrorismo excremental, como na deriva e no nomadismo dos personagens.

O reverso central desse poder se daria tanto na ação performática dos personagens soltos no espaço público em seus atos de subversão e transgressão como na hipotética tomada democrática do sinal sonoro de rádio no fim. Essa proliferação de loucos varridos que performatizam essa voz anônima para além de nós, normatizados no espaço físico e sonoro, representaria a própria população de desvalidos nos hospícios ou casas de correção soltos na rua, todos representantes da enorme horda humana de perturbados que não chegam a se constituir como lumpemproletariado, e formariam, assim, uma verdadeira tensão dionisíaca que funcionaria como uma terra de ninguém em direção à constituição de um pleno estado de anarquia.

O "trabalho" lúdico infantil, o singelo letreiro colorido feito por crianças no início do filme, conversaria, desta forma, tanto com os desenhos cinzelados na película no inicio e no fim do filme, no próprio modo superoitista de catar sons e imagens ao redor, assim como, inversamente, na distribuição de presentes excrementais pela cidade, também no colecionar destinos do caronista ou com o devaneio burlesco na teatralidade infantil e grotesca dos loucos soltos à esmo na praça em sua ambiguidade sexual interpretando super-heróis. $O$ ato pessoal em close da defecação, talvez fosse menos uma agressão ao público, como um Zé Celso no Teatro Oficina, e mais como escracho resistente, ponto de exclamação debochado despejado sobre o próprio expectador, herdado da cultura hippie, com seu estilo festivo que entrevia no orgiástico uma trincheira contra o homem massificado e vítima passiva da burocratização da sociedade tecnológica.

Haveria aqui o desejo de escapar ao controle no encontro selvagem com as imagens nascidas de seu imaginário remoto ou recolhidas ao redor e, poder entendêlas, proveria mais da acumulação das interpretações do que de sua justeza intrínseca. A desterritorialização aqui se encontraria exatamente na referência a Freud, mas longe de uma psicologia como parâmetro regulador da psique ou do comportamento social para o bem viver, mas simplesmente como mote para o destutelamento de colocar de forma escrachada o tema do polimorfismo perverso da infância e o foco na sexualidade e no comportamento louco ou liberto como guerrilha sem deixar de ser, ao mesmo 
tempo, uma forma narcísica de um jovem aparecer nas Jornadas de Cinema (como Navarro mesmo confessa).

Esse tipo de terrorismo excremental, mote do filme, personagem ou atitude saída possivelmente de figuras da fauna local de Salvador ou de outras cidades, funcionaria como a inspiração de uma grande recusa contracultural, de des-repressão e de manter vivo o desejo lúdico do adulto "criança" diante do quadro político repressivo que permanecia intenso no país. Utilizar, enfim, o cinema como expressão da dessublimação do princípio do prazer. Estes fluxos, tanto do intestino como do nomadismo, desregramento (intestinal) se encontrariam em oposição aos padrões de sociabilidade, às águas paradas do conservadorismo. Na dialética irônica entre o close da imagem do ato excremental e a fala, o verbo tentar, do "é preciso tentar", encontramos a impessoalidade do infinitivo, que significaria a luta entre a ambiguidade da boca-ânus, o blastóporo (mostrada no close da imagem) a independência dos sons, do gesto e dos ruídos elementares dos excrementos em relação crítica à representação imagética e verbal, o cérebro, o pensar, o verbo e a idealidade da frase constituída como superfície metafísica do poder de disjunção ou de dominação.

Desta forma atingiríamos o escracho através desse contraste entre a imagem despudorada inconsciente e a fala culta racional, portanto a comicidade, mas com isso, encontraríamos também a dimensão da articulação do individual com o político e a isso juntar-se-ia o final exprimido e expelido pelo filme de imagens e sons como as fezes pelo ânus, onde vê-se e ouve-se de tudo: da auto-resiliência do próprio filme no "devemos ser generosos o suficiente para compreender... que é uma questão de falta de amor" mas que que emenda na crítica psíquica ao regime militar no "por ter retenção anal", aos desenhos cinzelados na película, de orifícios, ao coração flechado, ao periquito, ao elenco cinzelado, à voz de Bethânia "torturada" e a locução radiofônica sobre as tropas de defesa do governo ditatorial cercando o palácio (identificando uma certa autoculpabilidade irônica devido ao filme, ter podido "dizer tudo" e desta forma deveria, supostamente, também se considerar ironicamente "culpado por subversão").

Todo esse entulho sonoro visual é colocado no fim da película justamente para que todo esse dejeto de imagens e sons possa funcionar como uma escrachada extirpação infecta, defecação feita pelo próprio filme, contra a determinação do poder ou mesmo dando um discreto "chega pra lá" neste imenso restolho infecto que representou até hoje a ditadura brasileira. Se a neurose é a sublimação como negação do corpo pelos padrões culturais e pelo progresso tecnológico, projetando o corpo reprimido nas coisas, o fato de Navarro incorporar-se imageticamente num homem que despeja seus monstros e se expressa jogando suas fezes, mostra sua verdadeira potência no sentido de identificar profundamente seu corpo com o momento político repressivo do país. 
A palavra visceral vem à tona, naquilo que Rubens Machado tinha observado em Navarro no que tange a registrar "a fruição da relação imediata corpo-espaço", que significaria que o cineasta parece, como na memorável performance nu que fez na Jornada de Cinema, engajar o próprio corpo e a voz quando filma, por isso seus filmes possuem, como lembra Marcos Pierry, "o despojamento de uma dicção própria e um frescor criativo", portanto, um caráter de vivacidade próprio á esse engajamento corpóreo. O corpo aqui parece, desse modo, atravessar o próprio enunciado, como se houvesse um pedido de presença do corpo na própria imagem. Procederia Navarro neste filme, $O$ Rei do cagaço, enfim, como uma forma perversa polimorfa escrachada, uma conspurcação lírica e suja de atingir o aparelho repressivo de um país conservador até a medula na sua retenção anal histórica, através do descobrimento do corpo perdido da infância. Liberta-se assim, evacuando o próprio tempo histórico expelido como excremento. 